\title{
A survey of Core Medical Trainees' opinions on the ePortfolio record of educational activities: beneficial and cost-effective?
}

\author{
${ }^{1} \mathrm{~S}$ Johnson, ${ }^{2} \mathrm{~A}$ Cai, ${ }^{3} \mathrm{P}$ Riley, ${ }^{4} \mathrm{LM}$ Millar, ${ }^{5} \mathrm{H}$ McConkey, ${ }^{6} \mathrm{C}$ Bannister \\ ${ }^{1}$ Medical student, Guy's, King's \& St Thomas' School of Medicine, Kings College London, UK; ' ${ }^{2}$ Medical Registrar, University Hospital \\ Lewisham, London; ${ }^{3}$ Senior House Officer, University Hospital Lewisham, London; ${ }^{4}$ Senior House Officer, St George's Hospital, London; \\ ${ }^{5}$ Senior House Officer, Guy's and St Thomas' NHS Trust, London; 'Senior House Officer, Epsom and St Helier's NHS Trust, Epsom, UK
}

\section{ABSTRACT}

Objectives: To evaluate Core Medical Trainees' (CMTs) opinions on the role of the ePortfolio in postgraduate education.

Design and setting: Cross-sectional survey of 91 CMTs in five NHS trusts within the South Thames Deanery.

Participants: Completed surveys were received from 80 Core Medical Trainees. Results: A total of $84 \%$ agreed that an ongoing record of progress is necessary, only $5 \%$ felt the ePortfolio represents value for money; $78 \%$ of respondents were unclear as to how the Freedom of Information Act (2000) impacts on the ePortfolio, and most were uninformed of the extent to which their entries can be accessed by third parties.

Conclusions: Trainees recognise the importance of recording ongoing progress, but most consider the ePortfolio to be poor value for money. There is uncertainty regarding ownership of information held on ePortfolio, and to what extent it can be accessed.There are inadequate opportunities to discuss concerns. This requires further deliberation and until things are clarified, trainees may not fully engage with the resource.

\section{KEYWORDS Postgraduate education, ePortfolio, medico-legal}

DECLARATION OF INTERESTS All authors except Ms Johnson used the ePortfolio as CMT trainees. The other authors have no interests to declare.
Correspondence to $\mathbf{S}$ Johnson 4 Compton Knoll Close, Plymouth PL3 5HS, UK

tel. +44 (0)7504 53606 I e-mail shona.johnson@kcl.ac.uk

\section{INTRODUCTION}

All doctors practising in the UK today are expected to comply with the standards of competence, care and conduct set out in the General Medical Council's (GMC) Good Medical Practice guide. The GMC's principles of good practice inform its assessment of fitness to practise and are currently being considered under several main headings: good clinical care, maintaining good medical practice, relationships with patients, working with colleagues, teaching/training probity and finally, health. The guide will be revised in 2012 .

The use of a portfolio fulfils the trainee's obligation to maintaining good medical practice: according to the GMC guide The Trainee Doctor, a portfolio should include a variety of evidence that may include skills assessments, involvement in teaching sessions and reflective practice in order to demonstrate achievement of the curriculum requirements, as well as continuing professional development (CPD) and self-directed learning. ${ }^{2}$ Learning portfolios are considered to support training and document a trainee's progress through the programme. They do not formally constitute an assessment of curriculum attainment according to the Gold Guide (which sets out the arrangements for specialty training), and do not constitute summative evidence of clinical or other skill/knowledge. ${ }^{3}$

The National Health Service (NHS) Education for Scotland (NES) ePortfolio was designed to be a secure digital record of educational activities including appraisals, workplace assessments, procedure competencies, examination results, presentations, audits and other achievements. It is also an ongoing personal development plan and a place for selfreflection on clinical events. ${ }^{4}$ It is the major tool used in auditing CMTs in their development during training. Every eight months, the deanery's specialty training (ST) head in Core Medical Training will review the portfolios to assess if each trainee is on track to complete the syllabus.

Since inception in 2005 , the ePortfolio principle has been developed and applied in over 20 different versions with over 35,000 medical, nursing/midwifery, dental and pharmacy trainees across the UK. ${ }^{5}$ All CMTs use the ePortfolio as part of their curriculum and training, and anyone on an Acute Care Common Stem (ACCS) (Medicine) course should 
have access. It is similar to the Foundation ePortfolio but with differing content at each stage of training allowing for the development of a single record of postgraduate education from Foundation Year I (FYI) through to specialty training. ${ }^{4}$

In the US, the last decade has seen a shift to certification of residency education based on outcomes rather than process. With a view to developing a nationwide programme for assessing six core competencies (similar to the GMC's seven) the Accreditation Council for Graduate Medical Education (ACGME) has been gradually implementing a web-based portfolio since 2007..$^{6}$ The ACGME Learning Portfolio (ALP) has a formative component: a record of self-reflective practice, feedback from supervisors and peers, plans for practice improvement, workplace-based evaluations of performance, and other qualitative assessments used by tutors to modify teaching and learning activities to improve student attainment. Unlike the NES ePortfolio however, the ALP is also intended for summative feedback, with achievement of clinical competencies being used to indicate how well the residency curriculum has been retained at the end of a training block. ${ }^{?}$

In Australia, the Postgraduate Medical Education Councils are placing greater emphasis on self-directed learning and regular formative assessment of junior doctors. In 2006, the Australian Curriculum Framework for Junior Doctors (ACF) was developed under the Confederation of Postgraduate Medical Education Councils (CPMEC). Three online national assessment tools were developed and piloted in April and June 2009 to assist in the assessment of the ACP:self-assessment, mid-term appraisal and end-of-term assessment. ${ }^{8}$ These assessments, along with recommendations that all junior doctors have goalsetting meetings at the beginning of a rotation," point toward the development of a standardised portfolio of appraisals, personal learning objectives and selfassessments, similar to the ePortfolio.

The European Union of Medical Specialists (UEMS) has developed standards in the key areas of postgraduate training: continuing medical education and professional development and quality assurance in practice. In 1993, its Charter on Training of Medical Specialists in the European Community determined that the activities and different stages of training should be recorded in a comprehensive logbook..$^{10}$ As yet, there doesn't appear to be a European equivalent to the established UK portfolios or those in development in the US and Australia.

Despite being a well-established part of CMT training in the UK, and in progress in other global healthcare systems, there has been very little in the literature describing trainees' experiences of the ePortfolio system. We carried out a multicentre study of five NHS trusts (King's College Hospital, Guy's and St Thomas' Hospital,
St George's Hospital, Epsom and St Helier's NHS Trust, and University Hospital Lewisham) to find out what CMTs' experiences are of the ePortfolio as an aid to their professional development.

\section{METHODS}

A questionnaire containing 14 statements covered three key areas of the ePortfolio: attitudes to cost, perceived effectiveness and CMTs' understanding of the legal standing of the ePortfolio.

Questionnaires were distributed via email directly to trainees, at teaching sessions and by distribution on wards.

Due to the focus of our study we only addressed trainees in Core Trainee year I (CTI) or year 2 (CT2). We wanted to maximise respondent candour and number of returned forms, so we intentionally did not collect any demographic data in order to keep forms anonymous. Respondents were not asked to disclose any personal information, although site of work could be determined upon collection of forms.

Participants were informed that the questionnaire was anonymous and that the data would be used to evaluate trainees' opinions towards the ePortfolio. Responses were graded as follows: strongly agree, agree, equivocal, disagree, strongly disagree. Replies were collected from November 2010 to January 20I I. Multiple efforts were made to contact trainees to maximise the response rate.

\section{RESULTS}

A total of 91 questionnaires were distributed to all of the CMTs within the hospital trusts: 80 (87.9\%) were returned. All were complete: $24(30 \%)$ responses were returned from King's College Hospital; I I (13.75\%) from University Hospital Lewisham; 19 (23.75\%) from St George's; 17 (21.25\%) from Guy's and St Thomas' Trust; and nine (I I.25\%) from Epsom and St Helier's Trust. The results are shown in Table I.

In our survey, only $5 \%$ of respondents felt that the ePortfolio represents good value for money; $93 \%$ disagreed or strongly disagreed that trainees should meet the full cost of the ePortfolio and $95 \%$ of respondents did not know how the registration fees for the ePortfolio are allocated.

\section{DISCUSSION}

\section{Cost of ePortfolio to trainees}

The cost of running the ePortfolio was incorporated into the enrolment fee of the Joint Royal Colleges of Physicians Training Board (JRCPTB) in 2009; enrolment is a requirement for all trainees. This cost, along with additional 
TABLE I Trainee responses to survey

\begin{tabular}{|c|c|c|c|c|c|c|}
\hline & & $\begin{array}{l}\text { Strongly } \\
\text { disagree } \\
\text { n (\%) }\end{array}$ & $\begin{array}{l}\text { Disagree } \\
\text { n (\%) }\end{array}$ & $\begin{array}{l}\text { Equivocal } \\
\text { n (\%) }\end{array}$ & $\begin{array}{l}\text { Agree } \\
\text { n (\%) }\end{array}$ & $\begin{array}{l}\text { Strongly } \\
\text { agree } \\
\text { n (\%) }\end{array}$ \\
\hline \multicolumn{7}{|c|}{ Cost of the ePortfolio } \\
\hline $\mathrm{Cl}$ & $\begin{array}{l}\text { Doctors should be required to keep a } \\
\text { record of ongoing assessment, their skills } \\
\text { and competencies }\end{array}$ & I (I) & I (I) & $11(14)$ & $5 I(64)$ & $16(20)$ \\
\hline $\mathrm{C} 2$ & $\begin{array}{l}\text { The ePortfolio represents good value for } \\
\text { money }\end{array}$ & $39(49)$ & $29(36)$ & $8(10)$ & $4(5)$ & $0(0)$ \\
\hline C3 & $\begin{array}{l}\text { Trainees should meet the full cost of the } \\
\text { ePortfolio themselves }\end{array}$ & $47(59)$ & $27(34)$ & $5(6)$ & I (I) & $0(0)$ \\
\hline C4 & $\begin{array}{l}\text { I know how the registration fees for the } \\
\text { ePortfolio are spent }\end{array}$ & $57(7 \mathrm{I})$ & $19(24)$ & $3(4)$ & $0(0)$ & I (I) \\
\hline \multicolumn{7}{|c|}{ Effectiveness of the ePortfolio } \\
\hline EI & $\begin{array}{l}\text { The NHS IT infrastructure adequately } \\
\text { supports ePortfolio-based assessment }\end{array}$ & $9(11)$ & $18(23)$ & $28(35)$ & $24(30)$ & I (I) \\
\hline E2 & $\begin{array}{l}\text { The electronic nature of the ePortfolio } \\
\text { facilitates rapid feedback }\end{array}$ & II (14) & $25(3 \mathrm{I})$ & $20(25)$ & $22(28)$ & $2(3)$ \\
\hline E3 & $\begin{array}{l}\text { The electronic nature of the ePortfolio } \\
\text { makes it easy to demonstrate my } \\
\text { competencies in an interview }\end{array}$ & II (14) & $23(29)$ & $24(30)$ & $21(26)$ & I (I) \\
\hline E4 & $\begin{array}{l}\text { Technical support for the ePortfolio } \\
\text { website is good }\end{array}$ & $9(11)$ & $23(29)$ & $37(46)$ & II (I4) & $0(0)$ \\
\hline E5 & $\begin{array}{l}\text { In principal, a web-based portfolio is } \\
\text { preferable to a paper-based portfolio }\end{array}$ & $6(8)$ & $7(9)$ & $21(26)$ & $34(43)$ & $12(15)$ \\
\hline \multicolumn{7}{|c|}{ Legal aspects of the ePortfolio } \\
\hline LI & $\begin{array}{l}\text { As an assessor, I know whether my } \\
\text { statements about other doctors' } \\
\text { performance can be legally challenged }\end{array}$ & $17(21)$ & $37(46)$ & $15(19)$ & $10(13)$ & $1(1)$ \\
\hline L2 & $\begin{array}{l}\text { It is clear how the Freedom of } \\
\text { Information Act (2000) relates to my } \\
\text { ePortfolio }\end{array}$ & $22(28)$ & $40(50)$ & $17(2 \mid)$ & I (I) & $0(0)$ \\
\hline L3 & $\begin{array}{l}\text { I know the extent to which the GMC can } \\
\text { access my ePortfolio and use its contents } \\
\text { as evidence at a Fitness to Practice hearing }\end{array}$ & $29(36)$ & $36(45)$ & $8(10)$ & $7(9)$ & $0(0)$ \\
\hline L4 & $\begin{array}{l}\text { I know the extent to which the civil and } \\
\text { criminal courts can access my ePortfolio } \\
\text { and use its contents as evidence during } \\
\text { a trial }\end{array}$ & $35(44)$ & $30(37)$ & II (I4) & $4(5)$ & $0(0)$ \\
\hline L5 & $\begin{array}{l}\text { I may fail to reflect on a situation for fear } \\
\text { that I will incriminate myself }\end{array}$ & $5(6)$ & $25(3 \mathrm{I})$ & $25(3 \mathrm{I})$ & $23(29)$ & $2(3)$ \\
\hline
\end{tabular}

pressures on the training budget for the Colleges contributed to a fee increase of $£ 56$ for a CMT and $E \mid 40$ for specialist training from 2009 to $2010^{11,12}$ At the time of developing our survey, the actual cost of the ePortfolio ( $£ \mid 8$ per trainee per year) was not made public to trainees; an open letter addressing trainee concerns over increased fees is now available on the news section of the JRCPTB website, but it is not widely publicised." Communication of this information to trainees was not adequate in this instance and this is likely reflected in trainee responses.
Value for money is a balance between economy, efficiency and effectiveness. Cost, quality, resource use, fitness for purpose and timeliness must be considered in order to judge whether or not these aspects of the ePortfolio together constitute good value. ${ }^{13}$ If one or more of these criteria is considered inappropriate then perceived value is reduced. The Best Evidence Medical Education (BEME) Guide II produced by NES suggests that medical students using reflective portfolios may be deterred from fully engaging in the process due to the 'substantial time commitment required'. ${ }^{14}$ This could lead to reduced use by CMTs and a poor value for money estimate as a result. 
Other factors influencing engagement with the portfolio include: a statement of explicit purpose, complete integration into the curriculum and assessment process, strong support by mentors and ease of use. ${ }^{15}$ Lack of any one of these factors may have reduced perceived value for money in our sample.

\section{Effectiveness}

Less than one-third of respondents considered that the NHS IT infrastructure supported the ePortfolio or that technical support was good. Respondents did not think that the ePortfolio facilitated rapid feedback or demonstrated clinical competencies. Other types of portfolios have been well-received among UK medical students; the BEME Guide II found improvements in student knowledge and understanding, greater self-awareness and engagement in reflection, and improved student-tutor relationships. ${ }^{14}$

Different eLogbooks have been used by surgical specialties in the UK for a decade with varying success. The Royal College of Surgeons of Edinburgh (RCSEd) initially developed the Faculty of Health Informatics (FHI) eLogbook in collaboration with the British Orthopaedic Association, used by every trauma and orthopaedics trainee since $2003 .{ }^{16}$ As of January 2006 it has been a Pan Speciality eLogbook in the UK and Ireland. ${ }^{17}$ Trainees can record operations and CPD credits and the logbook is used by trainers to inform appraisals, for reports in support of future re-validation or re-certification. ${ }^{17,18}$

The Intercollegiate Surgical Curriculum Programme (ISCP) Surgeon's log, a mandatory online tool for all British Specialty Registrar surgical trainees since 2007, was developed to log operations, create development plans and facilitate self-directed learning. There is limited information regarding trainees' experience of the ISCP, but in one survey of 539 users, the ISCP was deemed to be an ineffective system due to an apparent failure to engage trainees and thus achieve its full potential. This was attributed to inconvenience and lack of incentive for use, with time constraints and poor quality feedback being cited respectively. Moreover, the authors stated that the FHI eLogbook was being used instead by many respondents. ${ }^{20}$ Earlier this year, the joint Colleges decided to amalgamate all surgical logbooks, including the ISCP Surgeon's log, into the FHI eLogbook. ${ }^{21}$

We could find no studies which looked at trainees' opinions on these systems but the FHI logbook is currently being used by over 11,000 surgeons. The eLogbook Validation and Audit Committee (eVAC) and $\mathrm{FHI}^{16,19}$ reported the $\mathrm{FHI}$ logbook to be a very effective tool for the appraisal of surgical trainees, trainers and deanery programmes.

Another study looked at the depth of engagement with the reflective aspect of the ePortfolio by first year specialist trainees; large variation in the extent to which trainees both engaged in and documented evidence of reflection was found. The authors cited time constraints, a lack of understanding of the purpose of this section and a wariness to reflect on adverse events such as near misses in clinical practice, as possible reasons for this variation. ${ }^{22}$

Dental students in Newcastle (UK) trialling a web-based portfolio similar to the NES ePortfolio found the system to be easy to use and beneficial in terms of quantity, quality and potential for manipulation of data. However, they did not perceive it to effectively fulfil its key roles of aiding reflection and facilitating feedback due to confusion over the purpose of the portfolio as an aid to reflective practice, problems with the website support and insufficient training in using the system. ${ }^{23}$ The results of our study are in keeping with those of the last study to an extent: $58 \%$ prefer an electronic portfolio system; respondents are divided on whether the NHS IT infrastructure adequately supports the ePortfolio, and if the website's technical support is adequate; and only $31 \%$ respondents indicated that they consider the ePortfolio to facilitate rapid feedback.

We found no study in the literature that assessed the opinions of UK CMTs about how effective the ePortfolio is as a professional development tool for users. Our study showed that $84 \%$ of respondents agreed or strongly agreed with the need for an ongoing record of a trainees' progress, but only $27 \%$ of our sample felt the ePortfolio could help demonstrate their abilities in an interview. This is likely a result of disparity between the GMCs requirements of the portfolio (evidence of appropriate professional conduct by the individual and a platform from which to develop a greater self-awareness as a doctor) and the trainees' often mistaken expectations of it as evidence of their proficiencies and thus a summative document.

The purpose of the ePortfolio, and in particular reflective logs, needs to be made clearer and emphasised to trainees at the beginning of the process in order to avoid encouraging trainees' perceptions of it as a way of monitoring educational outcomes. A more thorough induction to the ePortfolio process, with particular emphasis on its role as a development tool rather than an assessment tool may improve levels of engagement and satisfaction.

\section{Understanding the legal standing of ePortfolio}

Most trainees surveyed were unclear as to who owns the information held in an ePortfolio. A large percentage of respondents were unaware of the potential implications of their entries in the ePortfolio when it came to the Freedom of Information Act 2000 (78\%), use in Fitness to Practice hearings $(81 \%)$, and in the criminal or civil courts $(81 \%)$.

The confidentiality of ePortfolio entries is not clearly defined. The ePortfolio section on the JRCPTB website states that shared contents of the portfolio can be seen 
by a number of individuals ranging from a trainee's supervisor, to the administrative staff of their deanery, to Annual Review of Competence Progression (ARCP) review panels in order to support the organisation and appraisal of a trainee's learning. Entries the owner chooses not to share remain private. ${ }^{4}$ What is not clear is whether this information is privileged in any way. The ePortfolio cannot be used in defence of a Fitness to Practice review as a record of educational activity; but there are no rules to indicate whether the reflective entries themselves could be grounds to instigate such a review.

According to the British Medical Association legal department, the confidentiality of portfolio entries has never been tested in civil or criminal litigation. Although it appears unlikely to be admissible, there is too much uncertainty regarding future uses of the Freedom of Information Act to give trainees long-term assurances. Coverage of the Freedom of Information Act is constantly reviewed, and there is no guarantee of immunity for trainees who wish to reflect on their mistakes in their portfolios. Trainees are not informed of this when they are given guidance on the use of ePortfolio; information regarding data ownership and confidentiality is limited in the GMC guidelines and on the JRCPTB and ePortfolio websites.

In the US, some hospital legal counsels have recommended that the reflective practices section be removed from portfolios due to the lack of definition regarding the privacy laws. ${ }^{24}$ According to the JRCPTB, selfreflection is not compulsory in the UK curricula, though the Colleges note that it is likely supervisors, tutors and ARCP panels will expect it; reflective logs are therefore 'highly recommended'. ${ }^{4}$

Thirty-three per cent of trainees admitted they may not fully engage with the reflective part of the ePortfolio because of possible ramifications. Given the above issues, these responses are not unexpected. Unless they are clarified, the fear of incriminating oneself may undermine the nature of the exercise as a tool for continuing professional development through reflective learning and feedback.

The efficacy of portfolios in postgraduate medical education remains unclear and there is a lack of evidence-based findings in the limited current literature to determine this, but they are being increasingly used at all levels. It is important to note that trainee understanding of the purpose of the ePortfolio will significantly inform the perception of effectiveness and costeffectiveness and therefore has the potential to vastly improve engagement and satisfaction levels.

The potentially negative consequences of documenting reflective practice on the individual's future career have not been adequately assessed, nor have there been sufficient opportunities for trainees to discuss these issues during orientation into the ePortfolio process. Although there have been no notable cases to date where the use of the ePortflio has resulted in negative repurcussions, and the legal standing of reflective portfolios has never been challenged, our results do suggest a degree of trainee concern about the potential for negative consequences.

\section{CONCLUSION}

The use of the ePortfolio is not perceived to be costeffective by CMTs in London's South Thames Deanery. Most trainees recognise the importance of having a record of progress, but do not feel that the current system represents a value for money investment: it is not clear from this study if trainees believe the reason to be that the cost is too high, the quality is too low, the product is not fit for purpose or simply that not enough time has elapsed to effectively judge these aspects together with the outcome of the process.

Clarification of ownership and confidentiality of portfolio entries, particularly reflective logs, is needed in order to protect the encompassing nature of the exercise; moreover, this clarification needs to be effectively communicated to trainees. Until these issues are addressed, trainees may not fully engage with the ePortfolio, and this will in turn undermine the benefits of such an exercise to continuing professional and personal development.

Acknowledgement: We would like to thank the late lan Noble, of King's College Hospital, London, who was the lead in designing the questionnaire.

\section{REFERENCES}

I General Medical Council (GMC) UK. The meaning of Fitness to Practise [Internet]. London: GMC. [cited 20I I Aug I8]. Available from: http:// www.gmc-uk.org/the_meaning_of fitness_to_practise.pdf_25416562.pdf

2 General Medical Council (GMC) UK. The Trainee Doctor [Internet] London: GMC. [cited 20II Aug 20]. Available from: http://www. gmc-uk.org/Trainee_Doctor.pdf_39274940.pdf

3 The Gold Guide. A Reference Guide for Postgraduate Specialty Training in the UK 2010 [Internet]. [cited 2012 Jan 28]. Available from: http:// www.mmc.nhs.uk/specialty_training/specialty_training_2012/gold_ guide.aspx

4 Joint Royal Colleges of Physicians Training Board (JRCPTB) [Internet]. ePortfolio FAQs. London: JRCPTB [cited 20I I Aug 18]. Available from: http://www.jrcptb.org.uk/ePortfolio/Pages/ePortfolio-FAQs.aspx

5 NHS Education for Scotland. NHS ePortfolio [Internet]. About the NHS ePortfolio. Edinburgh: NES [cited 20I I Aug 15]. Available from: https://www.nhseportfolios.org/Anon/AboutUs.aspx

6 Competency-based Learning Portfolio Advisory Committee. Status report to ACGME Board of Directors Executive Committee [Internet]. pp. 3-4. Chicago: Competency-Based Portfolio Advisory Committee; 1996 [cited 201 I Aug 23]. Available from: http://www. acgme.org/acWebsite/portfolio/cbpac_memo.pdf

7 Competency-based Learning Portfolio Advisory Committee. Status report to ACGME Board of Directors Executive Committee [Internet]. p. 19. Chicago: Competency-Based Portfolio Advisory Committee; 1996 [cited 201 I Aug 23]. Available from: http://www.acgme.org/ acWebsite/portfolio/cbpac_memo.pdf 
8 Confederation of Postgraduate Medical Education Councils (CPMEC) [Internet]. Australian curriculum framework resources. Melbourne: CPMEC. [cited 20II Aug 23]. Available from: http:// www.cpmec.org.au/Page/acf-resources

9 Australian Curriculum Framework (ACF). Guidelines for junior doctors using the national assessment tools [Internet]. p. 3. Brisbane: CPMEC. [cited 20II Aug 23]. Available from: http://www.cpmec.org.au/files/ Guidelines\%20for\%20JMOsv2.pdf

10 Union Europeene des Medecins Specialistes (UEMS)/European Union of Medical Specialists (EUMS). Charter on training of medical specialists in the European community [Internet]. Brussels: UEMS/ EUMS. [cited 20I I Aug 24] http://admin.uems.net/uploadedfiles/906.pdf

II Joint Royal Colleges of Physicians Training Board (JRCPTB). Open letter: response to trainee concerns over enrolment fee increase [Internet]. London:JRCPTB 2010 [cited 20II June].Available from: http://www.rcpe.ac.uk/training/files/jrcptb-fees-concerns-statement.pdf

12 Royal Colleges of Physicians and Surgeons of Glasgow. Fee increase [Internet]. London: JRCPTB [cited 20II Aug 24]. Available from: http://www.rcpsg.ac.uk/FellowsandMembers/BenefitsandServices/ lointheCollege/Pages/JRCPTB_Fees.aspx

13 Improvement Network. Value for money [Internet]. [cited 20I I Aug 24]. Available from: http://www.improvementnetwork.gov.uk/imp/ core/page.do?pageld $=1068398$

14 Buckley S, Coleman J, Davison I et al. The educational effects of portfolios on undergraduate student learning: a Best Evidence Medical Education (BEME) systematic review. BEME Guide No. II. Med Teach 2009; 31:282-98. http://dx.doi.org/I0.1080/01421590902889897

15 Driessen EW, van Tartwijk J, van der Vleuten $C$ et al. Portfolios in medical education: why do they meet with mixed success? A systematic review. Med Educ 2007; 41:1224-33. http://dx.doi. org/l0.IIII/j.1365-2923.2007.02944.x
I6 Jameson SS, Lamb A, Wallace WA et al. Trauma experience in the UK and Ireland: analysis of orthopaedic training using the $\mathrm{FHI}$ eLogbook. Injury 2008; 39:844-52. http://dx.doi.org/10.1016/j. injury.2008.03.030

17 Electronic Logbook Project [Internet]. Pan-Surgical Electronic ePortfolio for the UK and Ireland. [cited 20I I Dec I5].Available from: http://www. elogbook.org/

18 eLogbook Validation and Audit Committee. Who owns and has access to Trainee's individual eLogbook data? [Internet]. [cited 20II Dec I5]. Available from: http://www.elogbook.org/Portals/elogbook/documents/ Access_Trainees.pdi

19 Sher JL, Reed MR, Calvert P et al. Influencing the national training agenda. The UK and Ireland orthopaedic eLogbook. J Bone Joint Surg Br 2005;87:I I82-6.http://dx.doi.org/I0.I302/030I-620X.87B9.16433

20 Pereira EA, Dean BJ. British surgeons' experiences of mandatory online workplace-based assessment. J R Soc Med 2009; 102:287-93. http://dx.doi.org/ I0.1258/jrsm.2009.080398

21 Intercollegiate Surgical Curriculum Project (ISCP). Surgeon's Log [Internet]. [cited 20I I Dec 16].Available from: https://surgeonslog. iscp.ac.uk/

22 McNeill H, Brown JM, Shaw NJ. First year specialist trainees' engagement with reflective practice in the e-portfolio. Adv Health Sci Educ 2010; 15:547-58. http://dx.doi.org//0.1007/s I0459-009-92 I7-8

23 Vernazza C, Durham J, Ellis J et al. Introduction of an e-portfolio in clinical dentistry: staff and student views. Eur J Dent Educ 201 I; I5:36-4I. http://dx.doi.org/ I0. I I I I/j. I600-0579.2010.0063I.x

24 Nagler A, Andolsek K, Padmore JS. The unintended consequences of portfolios in graduate medical education. Acad Med 2009; 84: I 522 6. http://dx.doi.org/I0.1097/ACM.0b0I3e3/8Ibb2636

\section{RESPONSE FROM THE JOINT ROYAL COLLEGES OF PHYSICIANS TRAINING BOARD}

We are encouraged by the finding that $84 \%$ of respondents agreed or strongly agreed with the need for an ongoing record of trainees' progress.

The enrolment fee increase of 2009-10 is actually misrepresented. The fee was increased by $£ 28$ per year ( $£ \mid 8$ for the ePortfolio and $£ \mid 0$ for an increase in enrolment fee). JRCPTB spends $£ 3$ per year on ePortfolio development and support, and with the NHS Education for Scotland (NES) charge of $£ \mid 8$, the annual portfolio cost is $£ 2 I$ per trainee.

After discovering problems with technical support in $201 \mathrm{I}$, JRCPTB took over the help desk from NES. The response time to queries is now three working days or less.

The enrolment fee supports many activities: monitoring trainees' progress, recommending trainees for CCT, writing curricula, developing assessment methods, and providing external quality management advice to deaneries (full details are published in our short guide).'

We recognise the dangers highlighted in the discussion of using the ePortfolio as a source of summative educational outcomes. The JRCPTB group advising on workplacebased assessments has emphasised that the ePortfolio should be used for the formative development of trainees, and not to determine their progression.

We agree that there are unresolved issues which affect all Colleges in relation to data held in the ePortfolio and its potential use for disciplinary or medicolegal purposes. This needs to be addressed urgently, perhaps by joint action of the Academy of Medical Royal Colleges, BMA and GMC.

A number of improvements and enhancements to the ePortfolio are planned:

- Migration to a cloud server that will increase capacity and performance.

- A mobile assessment app for iPhones and iPads, due for release in May 2012.

- Programme allocation of all trainees on the ePortfolio to ensure they are linked to the correct curriculum, assessment forms and educational supervisors.

We are determined to work with our users and supplier, NES, to develop an effective (and cost-effective) ePortfolio.

\section{Reference}

I JRCPTB. A short guide to JRCPTB [Internet]. London: JRCPTB; [cited 2012 Feb 28]. Available from: http://www.jrcptb.org.uk/about-us/ Documents/JRCPTB\%20A\%20Short\%20Guide\%20Lft.pdf 